have many more observations, which I quoted earlier (8 October, p 918).

I accept their point about the shorter latent period for melanoma; but the evidence for nonlinearity in the incidence-exposure relation for melanoma is also relevant. Our differences of emphasis may reflect a concentration on shorter term effects by Professor MacKie and Dr Ryecroft and my concentration on the longer term outlook.

J MARK EI.WOOD

Department of Community Hedicine and Epidemiology,

Queen's Medical Centre, Nottingham NG72 UH

1 Marks R. Selwood TS. Solar keratoses. The association with erythemal ultraviolet radiation in Australia. Cancer 1985;56: 2332-6.

\section{Management of perinatal loss of a twin}

We are all indebted to Dr Elizabeth M Bryan for her contributions to our knowledge of the social and psychological effects of twinning and to Dr Manny Lewis for his studies of the need for mourning in relation to stillbirth - their latest joint paper (19 November, p 1327) being no exception. I wonder, however, whether they have sufficiently emphasised the conflict in a mother between mourning for the dead baby and taking pleasure in the rearing of a live one in the case of the death of one of a pair of twins. Either she postpones her mourning, repressing the feelings that go with it, or she indulges her grief at the expense of the survivor, depression being incompatible with the lively communication, based on primary maternal preoccupation, that Murray has shown to be so important for a baby's emotional and intellectual development.

Many of your readers will have personal or professional experience of the problem that this presents to families; and it is difficult to know how to cope with what on the face of it is an insoluble dilemma. Perhaps the best answer would be for the mother to be helped to get over her mourning before taking up the care of the second baby, bonding in our species being almost certainly a postponable if necessary process but susceptible to permanent wrecking.

JOHN A DAVIS

Department of Paediatrics,

Addenbrooke's Hospital, Cambridge ( $\mathrm{B} 22 \mathrm{QO}$

1 Murray $L$. The effects of postnatal depression on infant development: direct studies of early mother/infant interaction. In Kumar R, Brockington IF, eds. Motherhood and mental illness. Vol 2. Causes and consequences. Bristol: John Wright, 1988 159-90.

\section{Sexual drive of patients in psychiatric hospitals}

An anonymous correspondent (20-27 August, p 561) and Dr J C C Chase (29 October, p 1129) expressed concern about sexual activity in psychiatric hospitals, including rape. Rape may not be uncommon in such settings, and we are aware of three cases in units in which we have recently worked. Although rape arouses particular strength of feeling, it is only one example of the violence that is commonplace in psychiatric institutions. The amount of violence is thought to be rising, and the Department of Health has recently issued further guidelines.' ' There is, however, no consensus on whether or in what circumstances patients should be prosecuted for acts of violence committed in psychiatric hospitals.

Opinion among psychiatrists is divided on the question of prosecution. Some believe that those admitted to psychiatric wards enjoy a state of asylum which should, in most circumstances, extend to immunity from prosecution. Though few would dissent when acts of violence arise out of psychotic experience, many would contend that those who do not fall into this category should be held responsible for their actions and subject to the due process of law. Health care workers, particularly nurses, are increasingly reluctant to accept physical assault as an occupational hazard, and several cases have recently come to our attention of staff pressing charges against patients for violent attacks. These actions were initiated without the help or active support of hospital authorities and were met with hesitance from the police, who may be used to viewing psychiatric admission as an alternative to prosecution

Though it remains uncommon for patients to be charged after assaults on staff, the prosecution of patients for assault on other patients is, we suspect, less common still. We wonder which factors underlie whether the option of pressing charges is adopted or even considered. The reactions to the rape cases that we encountered bear examination in this respect. One case, the rape of a woman in her 70 s by a young schizophrenic, resulted in a decision to press charges. The patient's age, the feelings of her relatives, and the brutality of the attack may have influenced this choice of action. In the two remaining cases young female schizophrenics who were not acutely ill were raped by an outpatient and by a patient from an open ward. Staff adopted a "hot bath and cup of tea" approach, and the pressing of charges was not actively considered. We doubt that such an approach would have been chosen if the victims had been members of the nursing or medical staff.

The ethical, legal, and therapeutic implications of decisions to press charges against patients for assault remain largely unexplored. ${ }^{2+} \mathrm{We}$ are conducting a survey of the attitudes to and the practice of pressing charges and of the factors that influence these. We would be interested to hear from those with experience of decisions to press charges or otherwise, particularly regarding the eventual therapeutic implications.

DAVID JAMES

Department of Psychological Medicine SUNNY COLLINGS

Roval Free Hospital,

London NW3 2QG

1 Haller RM, Deluty RH. Assaults on staff by psychiatric in patients: a critical review. Br $\mathcal{Y}$ Psychiatry 1988;152:174-9.

2 Department of Health and Social Security. Violence to staff; report of the DHSS advisory committee on violence to staff. London HMSO, 1988

3 Hoge SK, Gutheil TG. The prosecution of psychiatric patient for assaults on staff: a preliminary empirical study. Hosp for assaults on staff: a preliminary

4 Miller RD, Maier GJ. Factors affecting the decision to prosecute mental patients for criminal behaviour. Hosp Community Psychiutry 1987:38:50-5.

\section{Drug Points}

\section{Immune thrombocytopenia and interferon alfa}

Drs Edward J Kanfer and Donald M McCarthy (Department of Haematology, Charing Cross and Westminster Medical School, Westminster Hospital, London SW1P 2AP) write: Recombinant interferon alfa has become a common treatment in patients with hairy cell or chronic granulocytic leukaemia. Its efficacy has also been investigated in several other haematological disorders. A thrombocytopenic effect of this agent has been observed frequently and this finding has been used in the management of essential thrombocythaemia.' We have recently seen a patient with lymphoma who developed a severe immune thrombocytopenia while receiving interferon alfa.

A 43 year old woman presented in 1982 with stage IV non-Hodgkin's lymphoma (small lymphocytic). Remission was induced, but this was followed by multiple relapses, culminating in severely symptomatic advanced disease. She achieved a partial remission with combination chemotherapy and in
March 1988 began receiving interferon alfa-2b (3 million units, 3 times weekly). At the start of this treatment her blood count showed a haemoglobin of $131 \mathrm{~g} / 1$, white cell count $5 \cdot 3 \times 10^{\%} / 1$, and platelet count $200 \times 10^{4} / 1$. Seven weeks later the dose of interferon was reduced to twice weekly because of leucopenia and thrombocytopenia (white cell count of $2 \cdot 3 \times 10^{\%} /$ and platelet count of $\left.30 \times 10^{\%} / \mathrm{l}\right)$. Over the next six weeks the cell count rose to $5.0 \times 10^{9} / 1$, although the platelet count remained low at $36 \times 10^{\%} /$. Two weeks later she presented with widespread purpura. A blood count showed a haemoglobin of $115 \mathrm{~g} / \mathrm{l}$, white cell count of $4.6 \times 10^{9} / \mathrm{l}$, and platelet count of $7 \times 10^{9} / 1$. Bone marrow examination showed a cellular marrow with many more megakaryocÿes than normal. Platelet associated immunoglobulin studies showed an IgG of $3800 \mathrm{ng} / 10^{6}$ platelets (normal $2-10$ ), IgM of $200 \mathrm{ng} / 10^{6}$ (normal $<2 \cdot 5$ ), and $\mathrm{C} 3 \mathrm{~d}$ of $40 \mathrm{ng} / 10^{\circ}$ (normal <3.3). The interferon was discontinued and she was started on prednisolone $(1 \mathrm{mg} / \mathrm{kg} / \mathrm{day})$. A rapid rise in her platelet count followed and the steroid dose was tapered over the next few weeks without event.

Interferon may cause thrombocytopenia by an inhibitory action on megakaryocyte progenitor cells. A recent study of patients receiving interferon has, however, shown raised levels of platelet associated immunoglobulins, ${ }^{2}$ suggesting that immune mediated platelet destruction may be important. The association of immune thrombocytopenia with non-Hodgkin's lymphoma is well recognised, ${ }^{3}$ but its development in our patient six years after presentation suggests that interferon may have been the precipitating cause. This interpretation is supported by both the study quoted above and previous reports which have associated interferon treatment with immune thrombocytopenia. ${ }^{+5}$ Physicians using interferon should be aware of this potential complication.

We thank Dr U Hegde for performing the platele associated immunoglobulin investigation.

I Giles FJ, Singer CRJ, Gray AG, et al. Alpha-interferon therapy for essential thrombocythaemia. Lancet 1988;ii:70-2.

2 Hunt BJ, Roter B, Davies SC, Hegde UM. Raised levels of platelet associated immunoproteins in the initial thrombocytopenia seen with alpha interferon therapy. $\mathrm{Br} \mathcal{f}$ Haemato cytopenia

3 Kaden BR, Rosse WF, Hauch TW. Immune thrombocytopenia in lymphoproliferative diseases. Blood 1979;53:545-51.

4 McLaughlin P, Talpaz. M, Quesada JR, Saleem A, Barlogie B, Gutterman JU. Immune thrombocytopenia following alphainterferon therapy in patients with cancer. JAMA 1985;254: interfer $1353-4$

5 Abdi EA, Brien W', Venner PM. Auto-immune thrombocytopen related to interferon therapy. Scand $\mathcal{F}$ Haematol 1986;36:515-9.

\section{Phenytoin toxicity produced by tolbutamide}

Ms Elizabeth Beech, Dr S V S Mathur, and Dr B P Harrold (Luton and Dunstable Hospital, Luton, Bedfordshire) write: We describe a patient maintained on phenytoin who developed phenytoin toxicity when given tolbutamide. A 48 year Asian woman with idiopathic epilepsy, diabetes mellitus, and ichaemic heart disease was transferred from another hospital. She was being maintained on phenytoin $200 \mathrm{mg}$ once daily, and her phenytoin concentration was $31.3 \mathrm{mg} / \mathrm{l}$. She had developed polydipsia and polyuria and her blood glucose concentration was $12-15 \mathrm{mmol} / \mathrm{l}$. Tolbutamide $500 \mathrm{mg}$ three times daily was started. Her symptoms did not resolve and after five days the tolbutamide was increased to $1 \mathrm{~g}$ three times a day. Within 48 hours she developed headache, nausea, cerebellar ataxia, and nystagmus. Her dose of phenytoin was reduced to $150 \mathrm{mg}$ at night and she was changed to insulin the same day. The phenytoin value the next day was $27 \cdot 4 \mathrm{mg} / \mathrm{l}$. The features of toxicity resolved completely within 48 hours. The rest of her medications remained unaltered. In 1982 she had been treated successfully for a year with phenytoin 100 $\mathrm{mg}$ at night and tolbutamide $1 \mathrm{~g}$ three times a day.

Wesseling and Mols-Thurkow investigated 17 epileptic patients taking phenytoin who were given tolbutamide $500 \mathrm{mg}$ two to three times a day.' The total plasma phenytoin concentration fell, but the proportion of free plasma phenytoin increased by $44.6 \%$ of control values. This displacement of phenytoin from plasma proteins lasted four days. None of their patients showed features of phenytoin toxicity during that phase. There is a single case report of ataxia and drowsiness when phenytoin and tolazamide were given for several weeks. ${ }^{2}$ 
Our patient had no features of phenytoin toxicity despite a concentration of $31.3 \mathrm{mg} / \mathrm{l}$. After starting tolbutamide the phenytoin concentration decreased to $27.4 \mathrm{mg} / \mathrm{l}$. The total concentration was measured, not the free level. Neither the Committee on Safety of Medicines nor the manufacturer knows of any othe cases of phenytoin toxicity produced by tolbutamide.

1 Wesseling $\mathbf{H}$, Mols-Thurkow I. Interaction of diphenylhydantoin (DPH) and tolbutamide in man. Eur $\mathcal{J}$ Clin Pharmacol 1975;8:75

2 Pannekoek JH, cited by Wesseling et al.

\section{Convulsion and coma after intranasal desmopressin in cystic fibrosis}

Drs E J Simmonds, M J Mahony, and J M Littlewoon (Regional Cystic Fibrosis Unit, St James's Hospital, Leeds LS9 7TF) write: Desmopressin has been advocated as a treatment for nocturnal enuresis. ${ }^{2}$ We report on a child with cystic fibrosis who developed water intoxication while being treated with desmopressin. The patient, a girl aged 13 years, had made good progress apart from recurrent nasal polyps requiring operative removal. By the age of 12 however, she had developed chronic Pseudomonas aeruginosa respiratory infection and began three monthly admissions for intravenous antibiotics During one of these she started taking intravenou azlocillin ( $5 \mathrm{~g}$ three times a day) and tobramycin $(130 \mathrm{mg}$ three times a day). Pancreatic and vitamin supplements were continued. She also had primary nocturnal enuresis resistant to normal therapeutic interventions so we decided to try desmopressin nasal spray. She was given four doses on consecutive nights: $10 \mu \mathrm{g}, 20 \mu \mathrm{g}, 20 \mu \mathrm{g}, 10 \mu \mathrm{g}$.

On the morning after her fourth dose of desmopressin the patient developed headache, nausea, and vomiting. She had remained dry for the first time the previous night. Review of her weight chart showed a sharp weight gain since treatment started: $41 \cdot 35 \mathrm{~kg}$ to $43 \cdot 15 \mathrm{~kg}$. On the third day of treatment serum sodium concentration had been $125 \mathrm{mmol} / \mathrm{l}$ and on the fourth day this had fallen to $114 \mathrm{mmol} / \mathrm{l}$. Later that day she had a convulsion lasting about five minutes and subsequently remained comatose. Her desmopressin was discontinued and she was managed with fluid restriction alone to prevent possible pontine myelinolysis.+ Twenty eight hours after her last dose of desmopressin she passed urine again and continued to pass good quantities of dilute urine. Forty hours after fluid restriction was started intravenous fluids with her normal daily sodium requirements were started. Her serum sodium concentration rose and five days later was normal $(135 \mathrm{mmol} / \mathrm{l})$.

Forty eight hours after her convulsion she was still deeply comatose, however. Physical examination showed response only to deep pain, poor corneal reflexes, absent cough reflex, and absent peripheral reflexes. Computed tomography of her head and lumbar puncture showed nothing abnormal. She gradually regained consciousness and over two weeks returned to normal with no neurological sequelae.

This patient with cystic fibrosis had a severe adverse response to intranasal desmopressin used in doses recommended by the manufacturer; several authors have reported that desmopressin by this route is safe for both short ${ }^{12}$ and long term' treatment of nocturnal enuresis. There are no reports of water intoxication, although mild side effects were noted in a few patients treated with intranasal desmopressin for diabetes insipidus. ${ }^{\circ}$ It is not clear why our patient responded as she did. The duration of action of nasally administered desmopressin is variable, ${ }^{7}$ depending on its rate of clearance from the nose. Our patient's nasal mucosa had the abnormal physical and electrical properties associated with cystic fibrosis as well as nasal polyps, so the duration of action of the drug may have been prolonged by any of these factors. In the light of what is known about the basic defect in cystic fibrosis it is tempting to speculate that this patient's sensitivity to desmopressin, resulting in abnormality of sodium and water homoeostasis, is linked to the chloride channel block described. ${ }^{\gamma}$ We would recommend that desmopressin should be used with great caution in children with cystic fibrosis or nasal polyps. At the very least careful weighing and frequent electrolyte measurements should be done.

1 Aladjen M, Wohl R, Boichis H, Ordo S, Lotan D, Freedman S Desmop
Dimsou SB. DDAVP and urine os
Arch Dis Child 1986;61:1104-7.

zaff $M$, Hoiby N, Fleusberg EW. Frequent antibiotic therapy improves survival of cystic fibrosis patients with chronic $651-7$.

4 Lasureno R, Karp BI. Pontine and extrapontine myelinolysis following rapid correction of hyponatraemia. Lancet 1988; : 1439-40.

5 Rew DA, Rundle JSH. An assessment of the safety of regular DDAVP therapy in primary nocturnal enuresis. Br $\mathcal{F} U$ rol (in press.

6 Marek J, Loutocky A, Pacovsky V, Zasoral M. Ten year experience with DDAVP in treatment of diabetes insipidus. Endokrinologie 1978;72:188-94.

Seif SM, Zenser TV, Garochi FF, Davis BB, Robinson AG. DDAVP (1-desamino-8-D-arginine-vasopressin) treatment of central diabetes insipidus: mechanism of prolonged antidiuresis. F Clin Endocrinol Metab 1978;46:381-8.

8 Quinton PM. Chloride impermeability in cystic fibrosis. Nature 1983;301:421-2.

\section{Severe hypersensitivity reaction to fenbufen}

Dr M M Muthiah (Bassetlaw District General Hospital, Worksop S81 0BD) writes: The common side effects of the non-steroidal anti-inflammatory drug fenbufen are mild gastrointestinal disturbance, rash, and neurological symptoms. ${ }^{2}$ The potentially serious side effects are peptic ulceration and gastrointestinal haemorrhage. I report here a serious systemic reaction.

A 41 year old previously healthy woman was given fenbufen $900 \mathrm{mg} /$ day for a painful left knee. She took it for 10 days, and four days after stopping the drug she developed a generalised erythematous rash and became unwell with throat pain, fever, and rigors. There was no history of arthritis, drug allergy, asthma, or eczema. On examination she was ill (temperature $40^{\circ} \mathrm{C}$ ) with generalised lymphadenopathy and an extensive erythematous exfoliative rash affecting the whole body and face. The left knee was swollen and tender. Investigations showed: haemoglobin $133 \mathrm{~g} / \mathrm{l}$, white cell count $42 \times 10^{9} / \mathrm{l}$, eosinophils $10 \cdot 1 \times 10^{4} / 1$, neutrophils $14.7 \times 10^{4} / 1$, platelets $139 \times 10^{\%} / \mathrm{l}$, prothrombin time $2.4 \mathrm{~s}$, activated partial thromboplastin time $41 \mathrm{~s}$ (control 21-32), fibrinogen normal. Aspartate aminotransferase activity was $1015 \mathrm{IU} / 1$ (normal 0-40), lactate dehydrogenase $2190 \mathrm{IU} / \mathrm{l}(230-460)$, alkaline phosphatase $1233 \mathrm{IU} / \mathrm{l}(100-280)$, and albumin $30 \mathrm{~g} / \mathrm{l}$. A PaulBunnell test, autoantibody screen, and toxoplasma antibody titres were all negative. Erythrocyte sedimentation rate, chest radiograph, radiograph of the left knee, and calcium and phosphate concentrations were normal. Immunoglobulins showed a polyclonal rise. On admission the bone marrow showed a grossly reactive picture with eosinophilia and increased mature lymphocytes.

Four days later she was deeply jaundiced with persistent fever. Repeat blood cultures were negative. Her haemoglobin started to drop and was $5 \mathrm{~g} / 110$ days after admission. Investigations confirmed a Coombs positive autoimmune haemolytic anaemia. Prednisolone $60 \mathrm{mg} /$ day was started, with considerable improvement in the jaundice and liver function within four days. At this stage a liver biopsy showed swollen liver cells with focal cholestasis. Portal areas contained polymorphs with proliferation of bile ductules. The appearances were those of a resolving hepatitis. Lymph node biopsy showed fatty infiltration with atrophy and no evidence of lymphoma. Liver function values continued to improve after two weeks of steroid therapy, and the haematological and liver function abnormalities completely resolved. She was discharged with advice against using nonsteroidal anti-inflammatory drugs. Follow up over a year confirmed that she was well with normal full blood count and liver function values.

Fenbufen was first marketed in the United Kingdom in 1980 and was the most commonly reported suspect drug on yellow cards in 1986 and $1987 .{ }^{3}$ Eighty per cent of these reports concerned mucocutaneous reactions, including erythema multiforme and Stevens-Johnson syndrome. There have been reports of allergic vasculitis, hepatitis with rash, haemolytic anaemia, and lymphadenopathy. Skin reactions have been reported with other non-steroidal drugs such as ibuprofen.

The onset of illness in relation to drug intake, eosinophilia, and other features such as rash, lymphadenopathy, and a hepatic picture raise the strong possibility of drug induced hypersensitivity in this patient. The rapid resolution of clinical and laboratory abnormalities with prednisolone was consistent with this. The differential diagnosis is angioimmunoblastic lymphadenopathy, which is known to occur as a hypersensitive reaction to therapeutic agents.

1 Brock PG, Jackson D. UK general practitioners' experience of fenbufen in elderly patients. Eur $\mathcal{F}$ Rheumatol Inflamm 1982;5:326-31.

2 Becker A, Hoffmeister RT. Fenbufen - a new non steroidal antiinflammatory agent in rheumatoid arthritis, its efficacy and toxicity. F Int Med Res 1980;8:333-38.

3 Committee on Safety of Medicines. Current problems No 23. 1988; Sept.

4 Sonnenblick M, Abraham AS. Ibuprofen hypersensitivity in systemic lupus erythematosus. Br Med $\mathcal{F}$ 1978; ;:619.

\section{Azapropazone induced hepatitis}

Drs T C N Lo and I W Dymock (Department of Medicine, Stepping Hill Hospital, Stockport) write: Hepatotoxicity is a rare but increasingly recognised side effect of most non-steroidal anti-inflammatory drugs, ${ }^{1}$ and several cases of fatal hepatitis have been reported. ${ }^{23}$ Nevertheless, complete recovery after early withdrawal of the offending drug usually occurs if the possible link is recognised. ${ }^{+}$We report a case of azapropazone induced hepatitis in which complete recovery followed withdrawal of the drug.

A 57 year old woman was given azapropazone (Rheumox) $600 \mathrm{mg}$ twice daily for osteoarthritis of both hips. Two weeks later she developed generalised erythema multiforme with slight involvement of the mucus membranes of the lips and mouth. She was admitted a week later with slight jaundice. There was no lymphadenopathy, hepatosplenomegaly, or ascites. She had no history of recent travel, contact with jaundiced patients, blood transfusion, injections, or tattoos. She was not taking other medication and did not abuse alcohol. Laboratory investigations showed: haemoglobin $133 \mathrm{~g} / \mathrm{l}$, white cell count $11.3 \times 10^{4} / 1$ with $4 \%$ eosinophils, plasma total bilirubin concentration $42 \mu \mathrm{mol} / \mathrm{l}$, aspartate transaminase $500 \mathrm{IU} / \mathrm{l}, \gamma$ glutamyltransferase $22 \mathrm{IU} / \mathrm{l}$, alkaline phosphatase $311 \mathrm{IU} / \mathrm{l}$, total protein $62 \mathrm{~g} / \mathrm{l}$ (albumin $35 \mathrm{~g} / \mathrm{l}$ ), prothrombin time $17 \mathrm{~s}$ (control 12). She was negative for antinuclear factor, antimitochondrial antibodies, and antismooth muscle antibodies and had had no recent infection with herpes simplex virus, Epstein-Barr virus, cytomegalovirus, varicella zoster, or rubella. Tests for hepatitis A and B were also negative.

Azapropazone was stopped and her jaundice and rash resolved within one week of admission. A percutaneous liver biopsy performed 10 days after admission showed mild centrilobular cholestasis, slight fatty change, and scanty inflammatory cells distributed widely throughout the liver parenchyma. The Kupffer cells were prominent and contained periodic acid Schiff positive, diastase resistant material. Several portal tracts showed moderate to severe chronic inflammatory change similar to that seen in chronic persistent hepatitis with occasional multinucleated giant cells and ill defined granuloma. The overall appearances were those of mild non-specific hepatitis with granuloma formation consistent with drug induced hepatitis. She remained well with normal liver function values one month and three months after discharge.

The manufacturers have received only two reports of "suspected" adverse reactions affecting the liver since azapropazone was marketed in 1976. In each case the link could not be substantiated because of lack of definite temporal relations between drug ingestion and the onset of symptoms and both patients were taking several drugs. The two week interval between the start of treatment and the onset of symptoms in our patient together with negative virological and immunological results suggested a drug induced hypersensitivity reaction, though the underlying mechanism is still unknown.' We have reported this case to the Committee on Safety of Medicines.

We thank Dr N L Reeve for his help in reporting the histological findings in this paper.

1 Ludwig J, Axelsea R. Drug effects on the liver. An updated tabular compilation of drugs and drug-related hepatic disease. Dig Dis Sci 1983;28:651-60.

Breen EG, McNicholl J, Cosgrove E, McCabe J, Stevens FM Fatal hepatitis associated with diclofenac. Gut 1986;27:1390-3. 3 Lee SM, Williams R. Subacute hepatic necrosis induced by piroxicam. Br Med $1984 ; 293: 540-1$.

Dunk AA, Sherlock SS. Diclofenac hepatitis. Br Med 1982;284:1065-6.

5 Williams R, Maddray W. Liver gastroenterology 4. London: Butterworth International, 1984:133-64. 